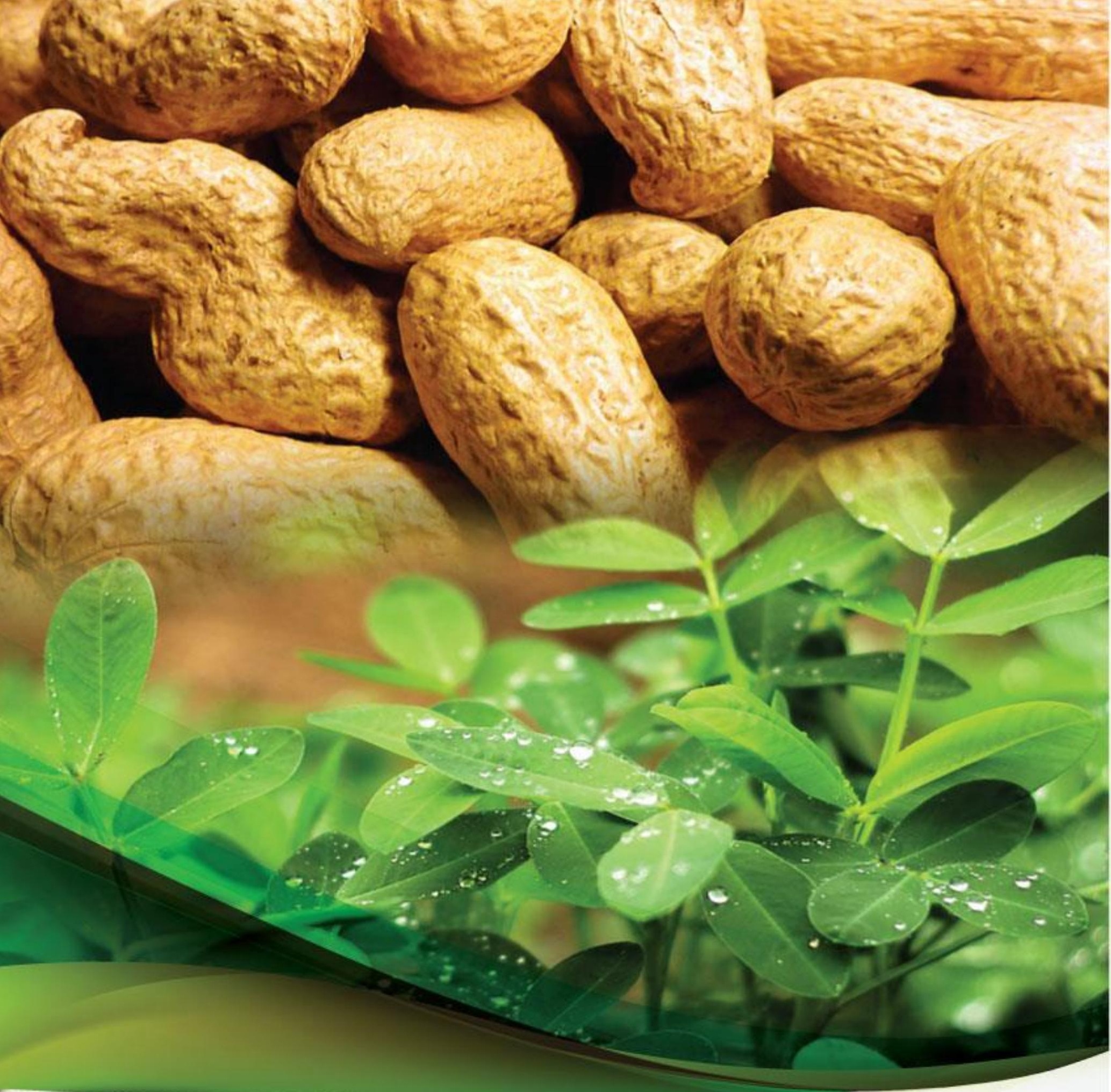

Amendoim (Arachis sp.) como fonte na matriz energética brasileira

Peanut (Arachis sp.) as a source in the Brazilian energy matrix

Liliane Garcia da Silva Morais RODRIGUES, Fernando Morais RODRIGUES,

Elisa Maria de Oliveira, Vanessa Bordin VIERA, Arturo Meléndez ARÉVALO,

Sérgio Luis Melo VIROLI 


\section{Amendoim (Arachis sp.) como fonte na matriz energética brasileira}

\section{Peanut (Arachis sp.) as a source in the Brazilian energy matrix}

\author{
OPPEN ACCESS \\ Liliane Garcia da Silva Morais \\ Rodrigues ${ }^{1,(D)}$ \\ Fernando Morais Rodrigues ${ }^{1,(1 D)}$ \\ Elisa Maria de Oliveira ${ }^{2}$, (D) \\ Vanessa Bordin Viera ${ }^{3,}$ (D) \\ Arturo Meléndez Arévalo ${ }^{4,}$ (D) \\ Sérgio Luis Melo Viroli ${ }^{1}$, (D) \\ 1 Instituto Federal do Tocantins-IFTO, \\ Campus. Paraíso, Paraíso do Tocantins, TO, \\ Brasil. \\ 2 Universidade Estadual do Amapá-UEAP. \\ Macapá, AP, Brasil. \\ 3 Instituto Federal do Amapá-IFAP. \\ Macapá, AP, Brasil. \\ 4 Universidade Federal Rural do Rio de \\ Janeiro-UFRRJ, Pós-Graduação em Ciência \\ e Tecnologia de Alimentos. Seropédica, RJ, \\ Brasil. \\ *Autor para correspondência: \\ lilianegarcia@ifto.edu.br
}

\section{Informações adicionais}

Recebido em: 11/10/2015

Aceito em: 15/05/2016

Publicado em: 30/09/2016

Editor:

Victor Hugo Gomes Sales

Instituto Federal de Educação, Ciência e Tecnologia do Amapá, Macapá, Amapá,

Brasil. jbfs@ifap.edu.br

Prot. $0802015 E D 01$

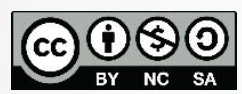

JBFS all rights

Copyright: (C) 2016

\begin{abstract}
ID JBFS0802015
DOI 10.18067/jbfs.v3i3.80

\section{RESUMO}

O biodiesel é um biocombustível renovável e sustentável. Nas últimas décadas a crescente demanda por energia e a consciência ambiental geraram grande, interesse na obtenção de combustíveis alternativos a partir de recursos renováveis, como o biodiesel. Todo o destaque dado ao novo combustível exige um estudo completo de toda sua cadeia produtiva. Entre as oleaginosas que se destaca, o amendoim é uma alternativa promissora para a obtenção de biodiesel. Nesse sentido, este estudo realizou pesquisa documental sobre a cultura oleaginosa do amendoim (Arachis sp.), pertencente à cadeia produtiva do biodiesel, a qual encontra-se inserida no Plano Nacional de Agroenergia. Considerando os aspectos vegetativos, ecológicos e econômicos da cultura oleaginosa amendoim, em relação à cadeia produtiva do biodiesel assume uma especial importância, em função de estar entre as culturas de ciclo curto. No entanto a viabilidade econômica torna-se um impasse em função das particularidades que envolvem o sistema de produção da cultura.
\end{abstract}

Palavras-chave: Arachis sp. Sustentabilidade. Óleos. Biocombustível. Produção

\section{ABSTRACT}

Biodiesel is a renewable and sustainable fuel. In recent decades the growing demand for energy and environmental awareness generates great interest in obtaining alternative fuels from renewable resources, such as biodiesel. All highlighting the new fuel requires a thorough study of all the productive chain. Among the oil that stands out, the peanut is a promising alternative for obtaining biodiesel. In this sense this study conducted documentary research on the oil crop peanut (Arachis sp.) Belonging to the biodiesel production chain, which is inserted in the National Agro-Energy Plan. Considering the vegetative, ecological and economic aspects of oilseed peanut regarding culture in the biodiesel production chain is of particular importance, due to be among the short cycle crops. However the economic viability becomes a standstill due to peculiarities involving the crop production system.

Keywords: Arachis sp. Sustainability. Oil. Biofuel. Production. 


\section{INTRODUÇÃO}

Os combustíveis fósseis são recursos energéticos não renováveis, e que, portanto, tendem a se esgotar com o passar do tempo, ${ }^{1}$ devido principalmente ao aumento da concentração do gás $\mathrm{CO}_{2}$ na atmosfera, produto da reação de combustão desses combustíveis, tem-se a ocorrência do efeito estufa e consequente aquecimento global. ${ }^{2}$ Nos últimos anos o aumento da demanda energética aliado à consciência ambiental, gerou grande interesse na obtenção de combustíveis alternativos a partir de recursos renováveis, como o biodiesel. ${ }^{3,4} \mathrm{O}$ biodiesel tem o potencial de reduzir a dependência sobre os recursos naturais e as emissões de gases com efeito de estufa. ${ }^{5}$ Em comparação com o diesel produzido a partir do petróleo, o biodiesel exerce um baixo impacto sobre o meio ambiente, sendo biodegradável e não tóxico, e tem baixas emissões de dióxido de carbono, material particulado e hidrocarbonetos não queimados. ${ }^{6}$ Nesse contexto, o biodiesel é uma alternativa atraente porque, além de ser renovável, atende à demanda ambiental pela redução de emissão de poluentes. ${ }^{7}$

A produção de biocombustíveis a partir de biomassa depende de dois principais fatores. Em primeiro lugar, a disponibilidade de matéria-prima para o biocombustível e, segundo, o processo adotado para produzir biocombustível. ${ }^{8}$

A agricultura de energia provém de quatro fontes de biomassa: as derivadas de fontes sacarinas e amiláceas, que geram o bioetanol; as derivadas de lipídios vegetais e animais, que geram o biodiesel; a fontes lignocelulósicas, que pode gerar o biometanol, bioetanol e biobutanol, briquetes ou carvão vegetal; e os resíduos e dejetos da agropecuária e da agroindústria, que podem gerar calor, biocombustíveis (biohidrogênio, biodiesel, bioetanol e biocarvão) e energia elétrica. ${ }^{9}$

O biodiesel pode ser obtido a partir de vários óleos vegetais ${ }^{4}$ ou de gordura animal, por transesterificação, em presença de álcoois de cadeias curtas e de catalisador básico, ácido ou enzimático dando origem a monoésteres de ácidos graxos e glicerina. ${ }^{7}$ As fontes renováveis representam hoje $43,8 \%$ da matriz energética nacional. A entrada desse novo combustível no mercado nacional vai gerar uma grande economia para o país, com a redução nas importações do diesel de petróleo. ${ }^{10}$

O uso de óleos vegetais como combustível alternativo possui mais de 100 anos quando o inventor do motor a diesel Rudolph Diesel testou o óleo de amendoim, enunciando a seguinte frase:

"O uso de óleos vegetais como combustível para motores pode ser insignificante atualmente, mas ao longo do tempo podem se tornar tão importantes como os produtos do petróleo". ${ }^{11}$

O amendoim (Arachis hypogaea $L$ ) é a quarta oleaginosa mais plantada no mundo, é empregado diretamente na alimentação humana (consumo in natura dos grãos), pode ser utilizado para extração do óleo (na indústria de conservas enlatadas) e em produtos medicinais. É considerada, entre as leguminosas, uma das mais importantes culturas. Além disso, o óleo de amendoim é uma alternativa promissora para a obtenção de biodiesel. ${ }^{12}$

A produção mundial de grãos de amendoim, para a safra 2012/13, foi estimada em 36,7 milhões de toneladas, e consumo mundial em 35,4 milhões de toneladas anuais de acordo com a Companhia Nacional de Abastecimento (CONAB); ${ }^{13}$ deste total, $60 \%$ são destinados ao esmagamento para extração do óleo comestível, gerando ainda um subproduto industrial (torta ou farelo), utilizado em ração animal; os $40 \%$ restantes, cerca de 8 milhões de toneladas, são utilizados como alimento humano, in natura, como componente de iguarias caseiras ou processados pela indústria de confeitaria.

Em 2015, a produção brasileira de amendoim apresentou um crescimento de $18,8 \%$ com relação ao ano anterior, devendo alcançar 371,489 mil toneladas de acordo com Levantamento Sistemático Produção Agrícola. ${ }^{14}$ São Paulo, o principal estado produtor, contribui com 252,1mil t (89\% da produção nacional), em uma área plantada de aproximadamente de 79,3 mil hectares. Outros estados que contribuem com a produção nacional são: Minas Gerais 9,3 mil t (2,9\%); Paraná 6,9 mil t $(2,2 \%)$ e Rio Grande do Sul com 5,2 mil t (1,6\%), representando em conjunto mais de $95,0 \%$ da produção nacional na safra 2012/2013. ${ }^{13}$

O óleo de amendoim pode apresentar perspectivas de produção competitiva de biodiesel. A semente seca de amendoim contém cerca de $50 \%$ de óleo, que apresenta em sua composição de 50$60 \%$ de ácido oleico, 18-30\% de ácido linoleico e 6- 
12\% de ácido palmítico. Do ponto de vista econômico, ele possui alto custo devido à exportação para fins alimentares. O cultivo do amendoim pode ser uma alternativa interessante no caso do Nordeste, pois pode ser empregado na rotação de cultura nos canaviais, o que viabilizaria a utilização desse óleo para produção local de biodiesel de forma competitiva ${ }^{15}$

Nesse sentido este estudo realizou pesquisa documental sobre a cultura oleaginosa do amendoim (Arachis sp.) pertencente à Cadeia Produtiva do Biodiesel, a qual encontra-se inserida no Plano Nacional de Agroenergia.

\section{Cadeia de produção de óleos vegetais no Brasil}

O Brasil, país tropical com dimensões continentais, dispõe de várias opções para a produção de óleos vegetais. O desafio é aproveitar ao máximo as potencialidades regionais e obter o maior benefício social da produção do biodiesel, aplicando a tecnologia tanto às culturas tradicionais como a soja, amendoim, girassol, mamona e dendê, quanto às novas como pinhão-manso, naboforrageiro, pequi, buriti, macaúba e grande variedade de oleaginosas a serem exploradas. ${ }^{10}$

No Brasil, com o modelo adotado para o desenvolvimento do Programa Biodiesel, a cadeia de produção desse biocombustível utiliza como principal matéria-prima espécies oleaginosas. A diversidade de culturas agrícolas (oleaginosas) a serem empregadas é grande e varia conforme as características de cada região ou Estado brasileiro. Para cada Estado e região do País, o desenvolvimento das cadeias produtivas das diferentes espécies oleaginosas precisa levar em consideração fatores que envolvem 0 meio ambiente e suas inter-relações com a sociedade moderna.

Campos $^{16}$ destaca para a região Norte, por exemplo, a utilização de matérias-primas como a palma, o babaçu, a soja e o amendoim. Na região Nordeste, as oleaginosas com destaque são o babaçu, a soja, a mamona, a palma (dendê), o algodão e o coco. Em relação ao Centro-Oeste, destaque para a soja, a mamona, o algodão, o girassol e o dendê. Para o Sul a soja, a colza, o girassol e o algodão. Para a região Sudeste a soja, o amendoim, a mamona, o algodão e o girassol.

\section{Cenário atual e potencial das principais oleaginosas}

Dentre as principais matrizes vegetais com grande potencial energético, estão a soja (Glycine max L.), o amendoim (Arachis sp.), o óleo extraído do cártamo (Carthamus tinctorius), da Mamona (Ricinus communis L.), do Girassol (Helianthus annuus), Algodoeiro (Gossypium sp.), além dessas espécies, existem outras fontes bioenergéticas que vem sendo exploradas na atualidade, como por exemplo o Pinhão-manso (Jatropha curcas) e o Dendezeiro ou Palma (Elaeis guineensis) no Estado do Rio Grande do Norte. ${ }^{17}$

No Brasil, o cultivo de oleaginosas é privilegiado devido a características climáticas e geográficas de certas regiões que favorecem 0 desenvolvimento de algumas culturas.

Conjuntamente com o álcool, os óleos vegetais compõem as principais fontes para obtenção de biocombustíveis. ${ }^{4}$ A tecnologia de produção de óleo diesel vegetal, por meio do processo de transesterificação metanólica é conhecida e aplicada, industrialmente em diversos países. ${ }^{18}$ No caso do Brasil, há necessidades de ajustes e adaptações para o uso do etanol como fornecedor do grupo éster que substitui a glicerina do complexo de triglicerídeos. A partir de óleos vegetais, por essa rota tecnológica é possível obter o biodiesel, com potencial energético equivalente ao petrodiesel, tendo como subproduto a glicerina. ${ }^{19}$

Essa rota, cuja primeira patente foi concedida à Universidade Federal do Ceará, adapta-se muito bem à produção em larga escala, tanto no sistema de batelada quanto no de fluxo contínuo.

Por esse motivo, a Embrapa e a Universidade de Brasília desenvolveram uma rota alternativa, por meio de um processo de pirólise e destilação fracionada, com ou sem o recurso de catalisadores. Esse processo resulta em quatro grandes grupos de biocombustíveis, cujas propriedades os aproximam do petrodiesel, da gasolina, do querosene e do gás de petróleo. Suas vantagens são a escala e a não produção de glicerina como um subproduto. ${ }^{20} \mathrm{Ainda}$ segundo o autor, equacionada a questão da tecnologia de processamento, é necessário atentar para outros aspectos da produção de biocombustíveis derivados de óleos vegetais, sendo estes: 
- Novo ponto de equilíbrio do mercado de oleaginosas, com a inserção da demanda energética no mercado de óleos e suas consequências para as tortas e farelos;

- Formulação de um plano de introdução gradativa dos biocombustíveis derivados de óleos vegetais na cadeia de consumo de motores de ciclo diesel, considerando o gradativo incremento da proporção de adição ao petrodiesel e a logística associada;

- Desenvolvimento tecnológico e análise ante os impactos econômicos, sociais e ambientais da expansão do uso de biocombustíveis derivados de óleos vegetais;

- Dimensionamento do mercado internacional e formulação do planejamento estratégico para apropriação da demanda incremental, baseado nos mesmos postulados para o etanol;
- Estudo dos impactos nas demais cadeias produtivas, em especial frangos, suínos e gado de corte.

\section{Características produtivas das principais oleaginosas}

Considerando os diversos tipos de óleos vegetais usados e os estudos matérias-primas brasileiras. Araújo et al. ${ }^{21}$ mostraram diferentes características físicas dos tipos vegetais em função da produção de biodiesel para extração do óleo de acordo coma tabela 1.

Entre os cultivos disponíveis (Tabela 2), merece destaque a soja - cujo óleo representa $90 \%$ da produção brasileira de óleos vegetais, dendê, coco, girassol (rendimento em óleo), e a mamona (resistência à seca). ${ }^{10}$

Tabela 1. Características físicas do óleo diesel e de alguns óleos vegetais.

Table 1. Physical characteristics of diesel oil and some vegetable oils

\begin{tabular}{lcccccccc}
\hline Parâmetros & Diesel & Amendoim & Soja & Algodão & Girassol & Babaçu & Dendê & Mamona \\
\hline $\begin{array}{l}\text { Densidade } \\
\text { relativa }\end{array}$ & 0,828 & 0,919 & 0,920 & 0,919 & 0,923 & 0,921 & 0,915 & 0,959 \\
$\begin{array}{l}\text { Visc. } \\
\text { Cinemática }\end{array}$ & $1,6-6,0$ & 38 & 36 & 40 & 37 & 32 & 39 & 297 \\
$\begin{array}{l}\text { Iń́cio } \\
\text { destilação }\end{array}$ & 165 & 173 & 152 & - & 211 & - & - & - \\
$\begin{array}{l}\text { Resíduo de } \\
\text { carbono }\end{array}$ & $0,3(\max )$ & 0,42 & 0,45 & 0,42 & 0,42 & 0,22 & - & 0,18 \\
$\begin{array}{l}\text { Número de } \\
\text { cetano }\end{array}$ & $45(\min )$ & 33 & 36 & 40 & 39 & 38 & 42 & - \\
$\begin{array}{l}\text { Poder calorífico } \\
\text { Inf. Kcal/I }\end{array}$ & 8.400 & 7.900 & 7.850 & 8.050 & 7.950 & 7.800 & 8.330 & 8.000 \\
$\begin{array}{l}\text { Água por } \\
\text { destilação }\end{array}$ & $<0,05$ & $<0,05$ & $<0,08$ & $<0,05$ & $<0,05$ & $<0,05$ & - & 0,20 \\
$\begin{array}{l}\text { Ponto de névoa } \\
\text { Enxofre }\end{array}$ & $9-19$ & 19,0 & 13,0 & 9,0 & - & 26,0 & - & - \\
\hline Fonte:Araújo & 1,3 & $<0,1$ & $<0,1$ & $<0,1$ & $<0,1$ & $<0,1$ & $<0,1$ & $<0,1$ \\
\hline
\end{tabular}

Fonte: Araújo et al. (2005) ${ }^{21}$.

Source: Araújo et al. (2005) 21 
Tabela 2. Características de culturas oleaginosas no Brasil.

Table 2. Characteristics of oleaginous crops in Brazil.

\begin{tabular}{lcccc}
\hline \multicolumn{1}{c}{ Espécie } & Origem do óleo & Teor do óleo (\%) & $\begin{array}{c}\text { Colheita } \\
\text { (meses/ano) }\end{array}$ & $\begin{array}{c}\text { Rendimento } \\
\text { (t/óleo/ha) }\end{array}$ \\
\hline Dendê/Palma & Amêndoa & 22,0 & 12 & $3,0-6,0$ \\
Coco & Fruto & $55,0-60,0$ & 12 & $1,3-1,9$ \\
Babaçu & Amêndoa & 66,0 & 12 & $0,1-0,3$ \\
Girassol & Grão & $38,0-48,0$ & 3 & $0,5-1,9$ \\
Colza/Canola & Grão & $40,0-48,0$ & 3 & $0,5-0,9$ \\
Mamona & Grão & $45,0-50,0$ & 3 & $0,5-0,9$ \\
Amendoim & Grão & $40,0-43,0$ & 3 & $0,6-0,8$ \\
Soja & Grão & 18,0 & 3 & $0,2-0,4$ \\
Algodão & Grão & 15,0 & 3 & $0,1-0,2$ \\
\hline
\end{tabular}

Fonte: Agência Nacional de Energia Elétrica. Adaptado pelo DPA/Mapa, 2006.

Source: National Agency of Electric Energy. Adapted by DPA/Mapa, 2006.

Já o Instituto Interamericano de Cooperação para Agricultura, complementou os dados apresentados (Tabela 3) entre as oleaginosas seu teor de óleo, produtividade por hectare e produção de óleo por hectare, onde:
Araújo et al. ${ }^{21}$ demonstraram o rendimento e a produtividade do óleo vegetal para algumas culturas oleaginosas (Tabela 4), e a composição centesimal de diferentes tortas (Tabela 5).

Tabela 3. Características de culturas oleaginosas no Brasil.

Table 3. Characteristics of oleaginous crops in Brazil.

\begin{tabular}{lccc}
\hline \multicolumn{1}{c}{ Oleaginosas } & $\begin{array}{c}\text { Teor de Óleo } \\
(\%)\end{array}$ & Produtividade (kg/ha.) & Produção de Óleo (kg/ha.) \\
\hline Amendoim & 50 & 2.800 & 1.400 \\
Mamona & 45 a 55 & 1.500 & 750 \\
Dendê & 22 & 20.000 & 5.000 \\
Soja & 18 & 2.200 & 600 \\
Buriti & 8 & 15 a 25.000 & 1.000 \\
Babaçu & 66,2 & - & 1.000 \\
Macaúba & 20 & 2.300 & 3.000 \\
Pinhão Manso & 48 & 5.000 & 3.000 \\
Girassol & 38 a 48 & 1.700 & 700 \\
Coco da Baia & 55 a 60 & - & 1.500 \\
Canola & 40 a 48 & 1.000 & 750 \\
Algodão & 20 a 30 & 1.800 & 450 \\
Nabo Forrageiro & 30 a 40 & 800 & 380 \\
Gergelim & 40 a 50 & 1.000 & 450 \\
\hline
\end{tabular}

Fonte: IICA.

Source: IICA. 
Tabela 4. Produtividade e rendimento de óleo vegetal.

Table 4. Productivity and yield of vegetable oil.

\begin{tabular}{lcc}
\multicolumn{1}{c}{ Tipos } & Grão $\left(\mathrm{Kg} / \mathrm{hm}^{2}\right)$ & Óleo $\left(\mathrm{L} / \mathrm{h} \mathrm{m}^{2}\right)$ \\
\hline Mamona (não irrigado) & $950-381$ & $450-1590$ \\
Algodão (irrigado) & $887-910$ & $150-370$ \\
Amendoim (irrigado) & $237-5160$ & $814-1780$ \\
Soja (irrigado) & $1980-3660$ & $383-650$ \\
Girassol (irrigado) & $1325-2470$ & $571-1030$ \\
\hline
\end{tabular}

Fonte: Araújo et al. (2005) ${ }^{21}$.

Source: Araújo et al. (2005) ${ }^{21}$.

Tabela 5. Composição centesimal de diferentes tortas.

Table 5. Centesimal composition of different pies.

\begin{tabular}{lcccc}
\hline \multicolumn{1}{c}{ Material } & Material seco & Proteína & Lipídios & Fibras \\
\hline Soja (grão) & 90 & 33,2 & 17,5 & 4,1 \\
Soja (torta) & 89 & 44,8 & 1,5 & 5,1 \\
Amendoim (grão) & 94 & 26,8 & 44,9 & 2,6 \\
Amendoim (torta) & 90 & 45, & 46,0 & 6,5 \\
Gergelim (grão) & 94 & 20,4 & 49,9 & 6,3 \\
Gergelim (torta) & 91 & 44,7 & 11,9 & 4,5 \\
Girassol (grão) & 93 & 14,3 & 32,5 & 28,2 \\
Girassol (torta) & 90 & 37,2 & 23,7 & 12,1 \\
Coco & 55 & 4,0 & 36,0 & 2,0 \\
Coco (torta) & 90 & 21,2 & 7,3 & 44,2 \\
\hline
\end{tabular}

Fonte: Adaptado de Araújo et al. (2005). ${ }^{21}$

Source: Adapted Araújo et al. (2005). ${ }^{21}$

\section{Amendoim (Arachis hypogaea L)}

O amendoim é uma oleaginosa originada da América, sendo utilizada como planta domesticada pelas civilizações indígenas sul-americanas há 3800 anos. As espécies do gênero Arachis são aquelas encontradas no Brasil, Paraguai, Argentina, Bolívia e Uruguai. As sementes de amendoim proporcionam elevada rentabilidade de óleo, proteínas e vitaminas, sendo importante fonte de energia e aminoácidos utilizada intensamente na alimentação dos indígenas antes da colonização. ${ }^{22}$

No século XVIII foi introduzido na Europa, no século XIX difundiu-se do Brasil para a África e do Peru para as Filipinas, China, Japão e Índia. Nos dias atuais o amendoim é um produto conhecido e apreciado em praticamente todos os países pelo seu incomparável sabor e versatilidade de uso em pratos salgados, doces e indústria. ${ }^{23}$ 
De acordo com o Sistema de Análise das Informações de Comércio Exterior via Web (ALICE Web) ${ }^{24}$, no Brasil em 2014, a exportação do amendoim atingiu 108,2 mil toneladas, movimentando U\$ 145,4 milhões de dólares um mercado no qual os principais importadores são os países da Europa e o Japão.

O Brasil, até o início do ano 1970, foi importante produtor de amendoim, ocupando papel expressivo tanto no suprimento interno de óleo vegetal quanto na exportação de subprodutos. A maior produção ocorreu em 1972, com 970 mil toneladas, sendo que o principal produto era o óleo, muito utilizado na culinária. A partir de 1974, devido entre outros fatores, à contaminação por aflatoxina e a maior disponibilidade de óleo de soja, o preço do produto nos mercados interno e externo caiu, desestimulando o plantio. A partir deste período até a década de 90 houve forte redução na área plantada e produção em nosso país. ${ }^{22}$

O uso de cultivares de porte rasteiro e mecanização das operações de plantio e colheita são tecnologias que também refletiram em maior produtividade. São utilizadas principalmente em São Paulo e no cerrado, onde o amendoim é cultivado em rotação ou em segunda safra.

A Embrapa Algodão, desde a década de 90, desenvolve tecnologias voltadas para 0 agronegócio da região Nordeste, trabalhando com culturas alimentares como forma de oferecer aos produtores regionais uma alternativa econômica de cultivo e que tenha relevante valor alimentar. ${ }^{25}$

\section{Características Vegetativas e Ecológicas}

Planta dicotiledônea, o amendoim é da família Leguminosae, subfamília Papilonoideae, gênero Arachis. As espécies mais importantes do gênero são $A$. hypogaea L., A. prostrata (Benth) e A. nhambiquarae (Hoehne). ${ }^{26}$

$\mathrm{O}$ amendoim cultivado (Arachis hypogaea L.) compreende as subespécies hypogaea e fastigiata, segundo classificação botânica. Esses grupos diferem entre si por um conjunto de caracteres morfológicos das plantas. Botanicamente, os representantes nativos da subespécie fastigiata são ainda classificados nas variedades fastigiata e vulgaris. ${ }^{27}$

\section{Necessidades edafoclimáticas da cultura}

O amendoim é cultivado em mais de 80 países nos dois hemisférios, principalmente em regiões tropicais na faixa de latitude $30^{\circ} \mathrm{N}$ e S. Apesar desta ampla adaptabilidade, a produtividade é fortemente influenciada por fatores ambientais, especialmente temperatura, disponibilidade de água e radiação, como qualquer outra cultura. ${ }^{27}$

Condições ambientais adversas reduzem o crescimento da planta, de maneira diferenciada, dependendo do estágio em que está se encontra vegetativo ou reprodutivo. $O$ efeito da temperatura é um dos mais estudados. Por exemplo, a temperatura é um fator que determina crescimento, eficiência da fotossíntese, havendo máxima eficiência destes quando as temperaturas diurnas e noturnas apresentam médias de $35^{\circ} \mathrm{C} / 25^{\circ} \mathrm{C} .^{28}$

O amendoim tem natureza hipógea, ou seja, os frutos desenvolvem-se debaixo do solo. Necessita, portanto, de solos de textura arenosa ou franco-arenosa para otimizar sua produção. Estes solos, contudo, são de baixa retenção hídrica e o manejo da água é imprescindível para melhor rendimento e economia no cultivo. 0 preparo de solo inicia-se com a limpeza da área (roçagem) e incorporação de restos de cultura, que pode ser feito com grade de disco. A seguir faz-se uma aração, se possível profunda e duas gradagens, a primeira para incorporação do calcário e complemento da aração e a segunda na época do plantio. Em áreas que se cultiva normalmente o amendoim, entretanto, procede-se uma aração, aplicando-se o calcário e, a seguir, uma gradagem para complementação da aração e incorporação do mesmo. Os equipamentos utilizados para estas operações podem ser a tração animal ou tratorizados. ${ }^{28}$

O solo deve ter $\mathrm{pH}$ na faixa de 6,0 a 6,2 . O suprimento de Cálcio e imprescindível para enchimento e formação das vagens e pode ser atendido através da calagem. A quantidade de calcário a ser aplicada é baseada nos resultados da análise da amostra de solo. Em caso de necessidade o calcário deve ser colocado no solo entre 30 e 45 dias antes do plantio. ${ }^{28}$ 


\section{Cultivares}

No Brasil, cultivares descendentes da subespécie Hypogaea, ${ }^{29}$ de porte rasteiro e ciclo longo (130 dias), estão sendo introduzidas nos sistemas de produção totalmente mecanizados, em regiões sem limitação quanto à disponibilidade de chuvas, ou onde não há restrições impostas pelos esquemas de rotação com outras culturas. Cultivares do grupo ereto precoce são as mais disseminadas nas diversas regiões brasileiras onde predominam pequenos produtores. ${ }^{28}$

Em sistemas de produção em que a colheita é manual ou semimecanizada, as plantas de porte ereto são as mais indicadas. A precocidade é requerida nas regiões onde $\mathrm{o}$ amendoim é cultivado em rotação com a cana-de-açúcar, e é um atributo vantajoso no controle de doenças ou de outros fatores de estresse. ${ }^{30}$

Cerca de $60 \%$ do mercado interno de amendoim é voltado para os materiais do tipo Valência, característicos por apresentarem porte ereto, ciclo em torno de 90 dias, vagens com 3 a 4 sementes de coloração vermelha e tamanho médio. A outra parte do mercado é voltada para os materiais do tipo Runner ou Spanish, ambos possuindo 1 a 2 sementes/vagem de coloração bege, cultivados em São Paulo e no Centro-Oeste.
Das 14 cultivares registradas no Registro Nacional de Cultivares, três são recomendadas para a região Nordeste: BR 1, lançada em 1994, BRS 151-L7, lançada em 1997 e BRS Havana, lançada em 2005. Desenvolvidas pela Embrapa Algodão, apresentam ciclo curto, porte ereto, adaptadas para cultivo no semiárido brasileiro e com grãos característicos para atender ao mercado interno de grãos in natura e indústria. ${ }^{23}$

A BR 1 tem baixo teor de óleo (45\%) e $29 \%$ de proteína bruta. Tem vagens com 3 a 4 sementes de formato arredondado e coloração vermelha. Ciclo médio é 90 dias e produz cerca de $1.8 \mathrm{t} / \mathrm{ha}$ de amendoim em casca no regime de sequeiro. 0 rendimento em sementes fica entre 71 a $73 \%$ (Figura 1). BRS 151 L7 é a mais precoce, com ciclo de 87 dias, possuindo vagens com 1 a 2 sementes alongadas, grandes e de coloração vermelha. A produtividade fica em torno de $1.8 \mathrm{t} / \mathrm{ha}$ no cultivo de sequeiro e o rendimento médio em sementes é de $71 \%$. 0 teor de óleo bruto nas sementes é $46 \%$ (Figura 2). A BRS Havana tem ciclo de 90 dias, produz $1.9 \mathrm{t} / \mathrm{ha}$ e tem rendimento de sementes na faixa de $72 \%$. Suas vagens contêm 3 a 4 sementes, de formato arredondado e coloração bege. Apresenta o menor teor de óleo entre as atuais cultivares em distribuição no Brasil, com média de $43 \%$ (Figura 3). ${ }^{23}$

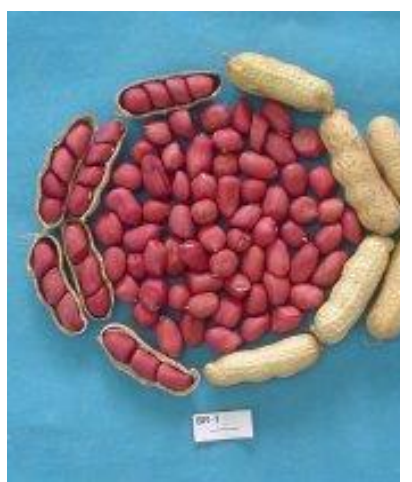

Figura 1. BR-1.

Foto: Silvokleio Costa.

Figure 1. BR-!

Photo: Silvokleio Costa.

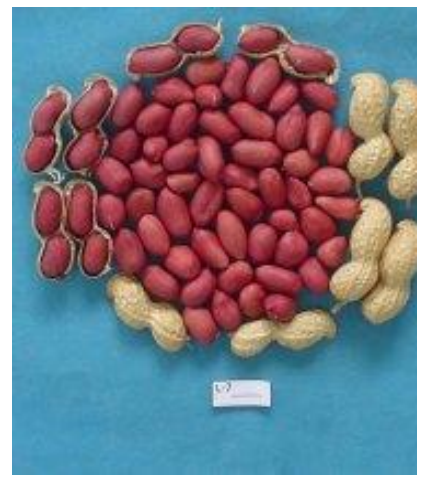

Figura 2. BRS 151 L-7.

Foto: Silvokleio Costa.

Figure 2. BRS 151 L-7

Photo: Silvokleio Costa.

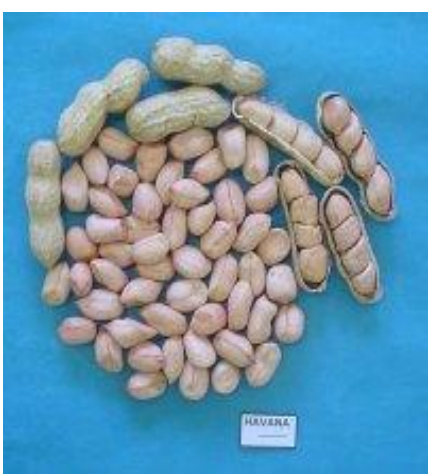

Figura 3. BRS Havana.

Foto: Silvokleio Costa.

Figure 3. BRS Havana

Photo: Silvokleio Costa. 


\section{Cadeia Produtiva do Amendoim: aspetos positivos, negativos e econômicos}

O amendoim possui cerca de $50 \%$ de óleo na amêndoa e já se constituiu em importante fonte de óleo comestível, antes de ser substituído pela soja. Igualmente, no início da década de 1980, foram realizados estudos no País, utilizando o óleo de amendoim em substituição ao óleo diesel, com grande sucesso. ${ }^{20}$

Em 1972, o Brasil produziu 962 mil toneladas de amendoim. Em virtude de uma série de desestímulos, a produção encolheu e, desde 1987, o Brasil não ultrapassava a marca de 200 mil toneladas (Figura 4).

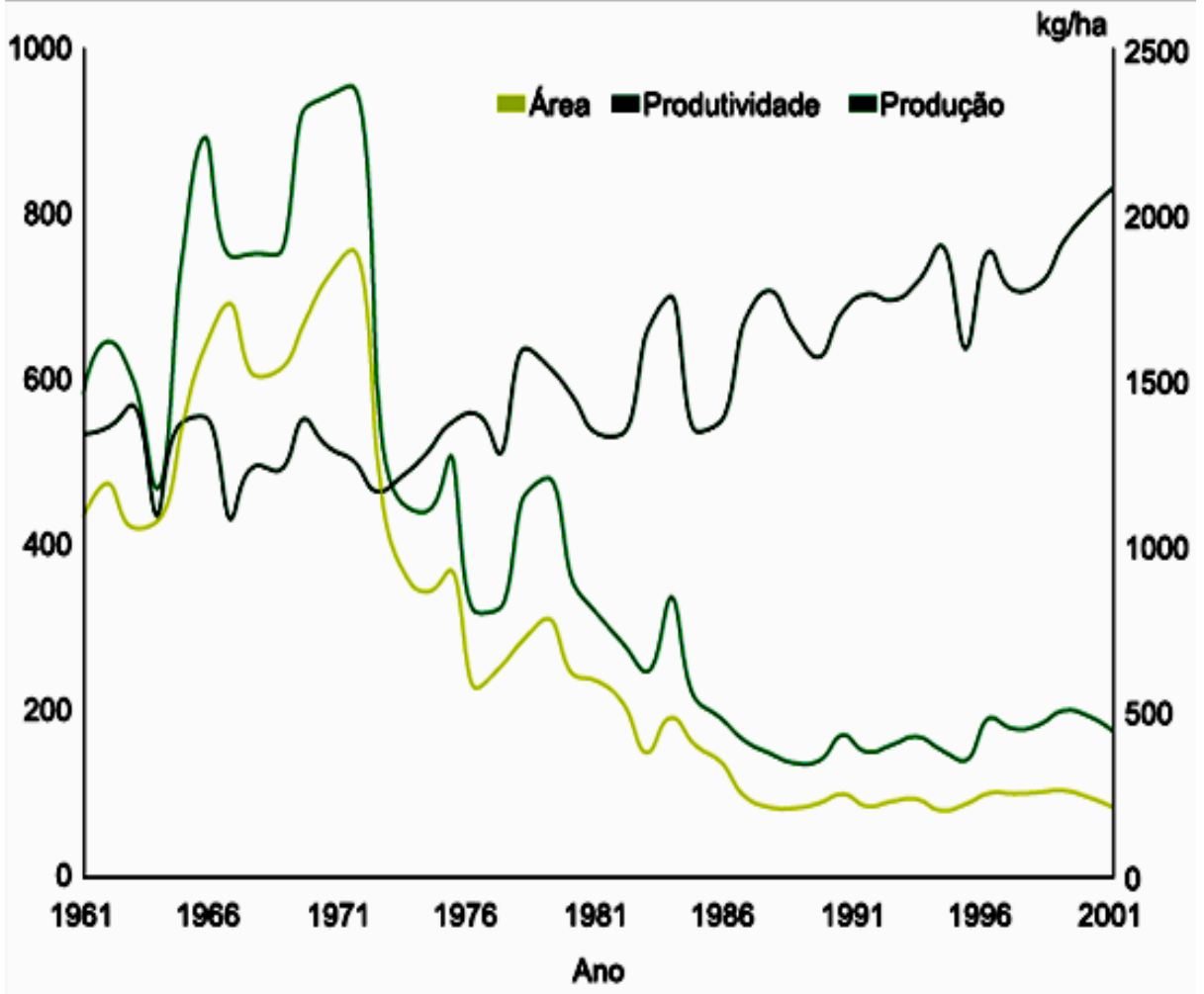

Figura 4. Produção, área plantada e produtividade do amendoim.

Fonte: FAO (2005). ${ }^{31}$

Figure 4. Production, cultivaded area and yield of peanuts.

Source: FAO (2005). ${ }^{31}$

Entre os fatores que contribuíram para a retração do plantio, destaque-se a baixa tecnologia usada pelos produtores, sendo constante a presença do fungo Aspergillus que, em condições de alta umidade, produz aflatoxina que, além de atacar as vagens, é cancerígeno ao ser humano.

Atualmente, estão disponíveis tecnologias que permitem a aplicação de boas práticas para o controle das micotoxinas e, em conseqüência, a retomada do cultivo do amendoim no Brasil. Outro fator importante foi a perda do mercado de óleo vegetal para produtos mais competitivos, em especial para a soja. A abertura do mercado energético pode conferir novo impulso para a cultura, dada sua alta capacidade de produção de óleo. Nos tetos de produtividade atuais, o amendoim permite extrair o dobro do volume de óleo por unidade de área, comparativamente à soja. ${ }^{20}$

A principal região produtora é o Sudeste, principalmente no Estado de São Paulo, onde o amendoim é cultivado em áreas de renovação de

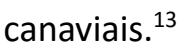


Outra possibilidade de expansão da cultura do amendoim, na Região Nordeste, é a sua utilização em consórcio com a mamona, podendo quase duplicar a produção de óleo por hectare. ${ }^{21}$

O panorama do cultivo de amendoim apresenta aspectos positivos em termos de produção e produtividade, e um dos fatores responsáveis pelo crescimento dos cultivos, é a utilização da tecnologia e boas práticas aplicada nas lavouras, refletindo diretamente no mercado nacional e internacional ao longo dos últimos anos, impacto que se pode observar, segundo dados do IBGE (Figura 5).

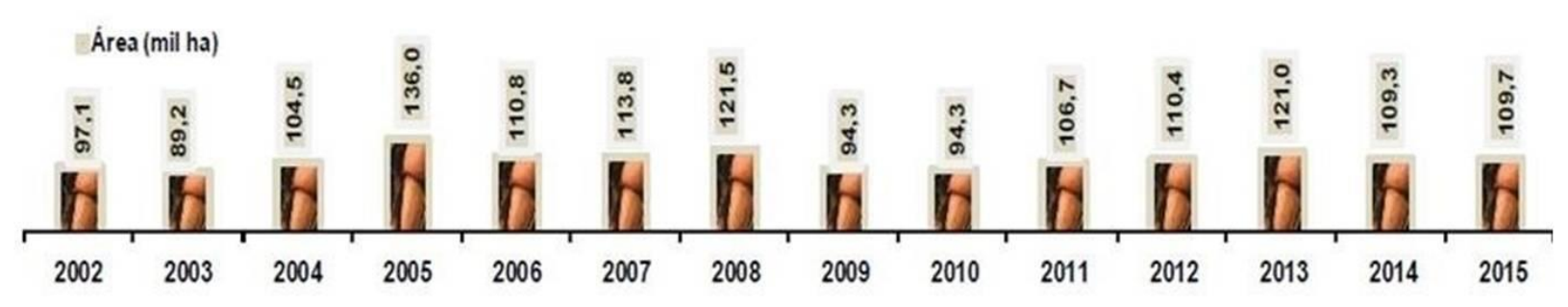

Produção (mil t)

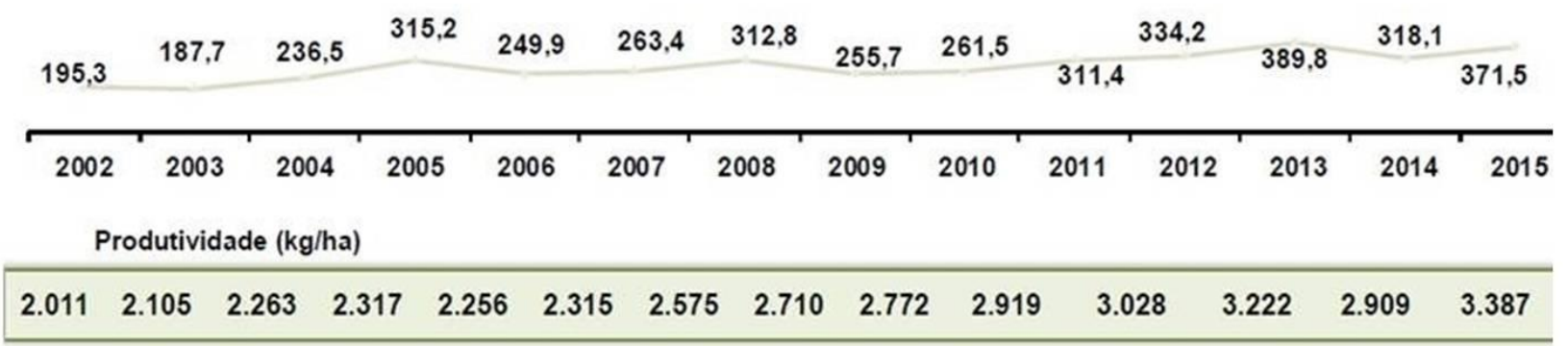

\begin{tabular}{lc}
\multicolumn{2}{c}{ VARIAÇÄO (\%) } \\
\hline ÁREA & $0,35 / 2014)$ \\
PRODUÇÄO & 16,8 \\
PRODUTIVIDADE & 16,4 \\
\hline
\end{tabular}

Figura 5. Produção, área colhida e produtividade do amendoim no Brasil.

Fonte: IBGE/LSPA (2015) ${ }^{14}$.

Figure 5. Production, harvested area and yield at peanuts in Brazil

Source: IBGE/LSPA (2015) ${ }^{14}$.

\section{Processamento do óleo}

Entre as oleaginosas comestíveis, o amendoim apresenta rendimento industrial superado apenas pelo girassol, com média de aproveitamento em torno de $40 \%$ para óleo e $50 \%$ para farelo. Predominantemente, é utilizado na indústria de gêneros alimentícios graças à nobre qualidade de seu óleo. O óleo do amendoim caracteriza-se como resistente à saturação, e de sabor agradável, nivela-se ao óleo de milho, de girassol e ao de oliva. Normalmente, cerca de $60 \%$ da produção mundial da oleaginosa é transformada industrialmente em óleo. Após a extração do óleo, se obtêm a torta ou farelo de amendoim, como coproduto de alto valor energético, com cerca de $45 \%$ de proteína, média de $8,5 \%$ de matéria graxa e, no máximo, $9,5 \%$ de celulose. ${ }^{32} 0$ aumento progressivo do consumo do óleo de amendoim tem impelido muitos lavradores a optar por sua cultura. A elevação do consumo vem sendo registrada, mesmo nas nações tradicionalmente consumidoras 
de azeite de oliva.

A extração de óleos vegetais pode ser feita por prensa hidráulica por batelada, prensa mecânica contínua e extração por solventes, porém a mecânica é tida como mais eficiente, de simples operação e baixo custo. Nesse processo algumas variáveis são importantes: cozimento e aquecimento dos grãos antes da prensagem, temperatura, tempo e teor de umidade dos grãos. ${ }^{33}$

A transesterificação é a reação química de um triacilglicerídeo com um álcool, formando ésteres e glicerol. Um catalisador é utilizado para aumentar a velocidade da reação e seu rendimento. A estequiometria para a transesterificação requer três mols de álcool e um mol de triacilglicerídeo para se obter três mols de ésteres alquílicos e um mol de glicerol. No entanto, a transesterificação pode atingir o equilíbrio da reação quando um excesso de álcool é utilizado, mas este excesso tem um limite, pois altas concentrações de álcool interferem na separação do glicerol devido a um aumento na solubilidade dos componentes. ${ }^{34}$

Segundo Kucek et al., ${ }^{35}$ a transesterificação apresenta altos rendimentos quando os parâmetros fundamentais, como a temperatura e tempo da reação, a concentração de catalisador e a razão molar, são otimizados. De acordo com Meher et al., ${ }^{34}$ a razão molar entre o álcool e o triacilglicerídeo é a condição operacional que mais afeta o rendimento em éster.

Os catalisadores utilizados para a transesterificação são classificados como alcalinos, ácidos, enzimáticos, ou heterogêneos, entre os quais os alcalinos, como hidróxido de sódio e hidróxido de potássio, são os mais efetivos. O hidróxido de sódio exibe a maior atividade catalítica no processo, mas apresenta problemas relacionados à dificuldade de recuperação do glicerol, além de exigir que o catalisador seja removido do produto final. ${ }^{34}$

\section{Aproveitamento dos resíduos}

Após o refinamento do óleo, o qual será utilizado nas indústrias da farmacologia, por obter maior pureza, o óleo de segunda, não refinado, serve como combustível das lâmpadas dos mineiros. E quando neutro, usa-se como lubrificante. Além de constituir-se como excelente matéria-prima para a indústria de saboaria. ${ }^{23}$

Após a extração do óleo de amendoim, obtém-se a torta (elevado valor comercial), que após processada dá origem ao farelo. O valor nutricional da torta é dependente da qualidade da semente, bem como da metodologia aplicada na extração do óleo. Além disso, outra aplicação para o farelo do amendoim é sua utilização como fertilizante, em função dos seus teores de nitrogênio (5 a $8 \%$ ) e fósforo (1,5\%). ${ }^{36}$

Durante a seca ou mesmo antes dela, as plantas que fornecem pastagens sofrem o processo da floração, tornando-se endurecidas e imprestáveis para a alimentação. Assim o criador deve dar suplementação alimentar aos animais para compensar a deficiência do pasto.

$\mathrm{O}$ amendoim ainda pode ser aproveitado na fenação. Trata-se de um dos recursos mais eficientes e econômicos para a conservação da forragem, e nos últimos anos em São Paulo muito se tem feito nesse sentido com as leguminosas que apresentam indiscutível superioridade sobre as demais forragens. O feno produzido a partir do amendoim é bem mais rico em proteínas e vitaminas, rendendo também muito mais em quantidade de massa. ${ }^{12}$

$\mathrm{O}$ amendoim se destaca dentre as leguminosas e além do emprego diversificado das suas sementes, as hastes, quando convenientemente preparadas, constituem forragem de grande valor alimentício para os animais, principalmente para o gado leiteiro. ${ }^{12}$

\section{CONCLUSÕES}

Considerando os aspectos vegetativos, ecológicos e econômicos da cultura oleaginosa, em relação à cadeia produtiva do biodiesel, o amendoim assume uma especial importância, em função de estar entre as culturas de ciclo curto.

Além disso, pôde-se considerar que a utilização do óleo de amendoim como matériaprima para a produção do biodiesel não é tão viável, pois se trata de um óleo com características nobres, ou seja, farmacologia e indústria alimentícia.

Contudo, o aproveitamento dos resíduos agrícolas e de coprodutos tornam-se indispensáveis para o ganho ambiental na área produtiva, o que traz aos coprodutos a redução de custos de produção e o beneficiamento da matéria-prima.

Trabalhos futuros devem ser dirigidos pela complementação do estudo ora apresentado, 
incluindo a análise econômica de processo de produção de torta, e de produção do óleo.

\section{CONTRIBUIÇÃO DOS AUTORES}

Todos os autores participaram realizando o levantamento bibliográfico e a elaboração da revisão.

\section{CONFLITO DE INTERESSE}

Os autores declaram que não há conflito de interesse.

\section{FINANCIAMENTO}

Os autores reportam que não houve suporte e auxílio financeiro para a elaboração da revisão bibliográfica.

\section{COMO CITAR ESSE DOCUMENTO}

\section{ABNT}

RODRIGUES, Liliane Garcia da Silva Morais et al. Amendoim (Arachis sp.) como fonte na matriz energética brasileira. Journal of bioenergy and food science, v.3, n.3, 178-190 2016. DOI:10.18067/jbfs.v3i3.080

\section{APA}

Rodrigues, L., Rodrigues, F., Oliveira, E., Viera, V., Arévalo, A., \& Viroli, S. (2016) Peanut (Arachis sp.) as a source in the Brazilian energy matrix. Journal of bioenergy and food science, 3(3) 178-190. DOI:10.18067/jbfs.v3i3.080.

\section{REFERÊNCIAS BIBLIOGRÁFICAS}

1. SPEIRS, J.; MCGLADE, C.; SLADE, R. Uncertainty in the availability of natural resources: Fossil fuels, critical metals and biomass. Energy Policy, v.87, p.654-664, 2015. DOI 10.1016/j.enpol.2015.02.031

2. CLOY, J. M.; SMITH, K. A. Greenhouse Gas Emissions. In: (Ed.). Reference Module in Earth Systems and Environmental Sciences: Elsevier, 2015. ISBN 978-0-12409548-9

3. LOPES, D.; STEIDLE, N. Potential crops for biodiesel production in Brazil: a review. World Journal of Agricultural Sciences, v.7, n.2, p.206-217, 2011.

4. DEMIRBAS, A. Biofuels sources, biofuel policy, biofuel economy and global biofuel projections. Energy Conversion and Management, v.49, n.8, p.2106-2116, 2008. DOI 10.1016/j.enconman.2008.02.020

5.OMER, A.M. Green energies and the environment, Renewable and Sustainable Energy Reviews, v.12, n.7, p.1789-1821, 2008. DOI 10.1016/j.rser.2006.05.009

6.LEE S.; POSARAC, D.; ELLIS, N. Process simulation and economic analysis of biodiesel production processes using fresh and waste vegetable oil and supercritical methanol, Chemical Engineering Research and Design, v.89, n.12, p.2626-2642, 2011. DOI 10.1016/j.cherd.2011.05.011

7.FU, Q.; SONG, C.; KANSHA, Y.; LIU, Y.; ISHIZUKA, M.; TSUTSUMI, A. Energy saving in a biodiesel production process based on self-heat recuperation technology. Chemical Engineering Journal, 278, 556-562. 2015. DOI 10.1016/j.cej.2014.11.027

8.SAJID, Z.; KHAN, F.; ZHANG, Y. Process simulation and life cycle analysis of biodiesel production. Renewable Energy, v.85, p.945-952. 2016. DOI 10.1016/j.renene.2015.07.046

9.ALVIM, J.C.; ALVIM, F.A.L.S.; SALES, V.H.G.; SALES, P.V.G.; OLIVEIRA, E.M.; COSTA, A.C.R. Biorrefinarias: Conceitos, classificação, matérias primas e produtos. Journal of Bioenergy and Food Science, v.1, n.3, p.61-77, 2014. DOI 10.18067/jbfs.v1i3.22

10. BRASIL. Ministério das Minas e Energias. Agência Nacional do Petróleo, Gás Natural e Biocombustíveis (ANP). Resolução $\mathrm{n}$-42 para análises de qualidade do biodiesel. Brasília, 2006.

11. SHAY, E. G. Diesel fuel from vegetable oil: status and opportunities. Biomass Energy, v.4, n.4, p.227-242, 1993. DOI 10.1016/0961-9534(93)90080-N

12. PIGHINELLI, A.L.M.T. Extração mecânica de óleos de amendoim e de girassol para a produção de biodiesel via catálise básica. 2007. 93f. Dissertação (Mestrado em Engenharia Agrícola) - Faculdade de Engenharia Agrícola, Universidade Estadual de Campinas, Campinas, 2007.

13. COMPANHIA NACIONAL DE ABASTECIMENTO (CONAB). Acompanhamento da safra brasileira de grãos. 2014.

14.LSPA-Levantamento Sistemático Produção Agrícola. Rio de Janeiro v.29 n.2 p.1-83, fevereiro de 2015.

15.ALLEONI L.R.F.; BEAUCLAIR E.G.F. Cana-de-açúcar cultivada após milho e amendoim. Scientia Agricola, v.53, n.3, p.409-415, 1995.

16.CAMPOS, I. Biodiesel e Biomassa: duas fontes para o Brasil. Revista de Ecologia do Século 21, Rio de Janeiro, v.80, 2003.

17.MEDEIROS, A. R. S. Análise da viabilidade ambiental, econômica e operacional da produção de biodiesel a partir de microalgas. 50f. Dissertação (Mestrado). Universidade de Potiguar, Rio Grande do Norte, Natal. 2014.

18.FUKUDA, H.; KONDO, A.; NODA, H. Biodiesel fuel production by transesterification of oils. Journal of Bioscience and Bioengineering, v.92, n.5, p.405-416, 2001. DOI 10.1016/S1389-1723(01)80288-7 
19.DE CASTRO, H.F. et al. Modificação de óleos e gorduras por biotransformação. Química Nova, v.27, n.1, p.146156, 2004. DOI 10.1590/S0100-40422004000100025

20.PERES, J.R.R; FREITAS JUNIOR; E; GAZZONI, D.L. Biocombustíveis: Uma oportunidade para o agronegócio brasileiro. Revista Política Agrícola, Ano XIV - № 1 Jan./Fev./Mar, p. 31-41, 2005.

21.ARAÚJO, K.M; OLIVEIRA, A.K.C; COSTA, G.B; QUEIROGA, R. N. G; PANNIR SELVAM, P.V. Estudo comparativo técnico e econômico de diferentes óleos vegetais brasileiros para produção de Biocombustível. 2005.

22.GODOY, I.J.; MORAES, S.A.; ZANOTTO, M.D.; SANTOS, R.C. Melhoramento do Amendoim. In: BORÉM, A. (Ed.). Melhoramento de espécies cultivadas. 2 ed. Viçosa: Universidade Federal de Viçosa,. P.51-102. 2004.

23.SUASSUNA, T.M.F.; SANTOS, R.C.; GONDIM, T.M.S. Importância Econômica. In: Cultivo do Amendoim. Campina Grande: Embrapa Algodão, 2006. (Embrapa Algodão. Sistema de Produção Técnica, 7).

24.ALICE WEB-Sistema de Análise das Informações de Comércio Exterior via Internet. [S.I], 2015. Acesso em 06 mai. 2015.

25.FREITAS, S.M.; MARTINS, S.S.; NOMI, A.K; CAMPOS, A.F. Evolução do mercado brasileiro de amendoim. In: SANTOS, R.C. O agronegócio do amendoim no Brasil. Campina Grande: Embrapa Algodão, 451p. 2005.

26.BOLONHEZI, D.; GODOY, J.I.; SANTOS, R.C. Manejo cultural do amendoim. In: SANTOS, R.C. dos (Ed. Téc.). In: O agronegócio do amendoim no Brasil. Campina Grande: Embrapa Algodão, p.193-244. 2005.

27.KRAPOVICKAS, A.; GREGORY, W.C. Taxonomía del género Arachis (Leguminosae). Bonplandia, v.8, n.1-4, p.1-186, 1994.

28.GODOY, I.J.; MORAES, S.A.; SIQUEIRA, W.J.; PEREIRA,
J.C.V.N.A.; MARTINS, A.L.M.; PAULO, E.M. Produtividade, estabilidade e adaptabilidade de cultivares de amendoim em três níveis de controle de doenças foliares. Pesquisa Agropecuária Brasileira, v.37, n.7, p.1183-1191, 1999.

29.GODOY, I.J.; MORAES, S.A.; TURATTI, J.M.; PEREIRA, J.C.V.N.A.; MARTINS, A.L.M.; PAULO, E.M. IAC Caiapó: novo cultivar de amendoim. Campinas: Instituto Agronômico, 1996.

30.MORAES, S.A.; GODOY, I.J.; MARTINS, A.L.M.; PEREIRA, J.C.V.N.A.; PEDRO JÚNIOR, M.J. Epidemiologia da mancha-preta (Cercosporidium personatum) em amendoim: resistência, controle químico e progresso da doença. Fitopatologia Brasileira, v.19, n.4, p.532-540, 1994.

31.FAO. Food and Agriculture Organization of the United Nations. FAO Statistical Databasis.

32.TASSO JUNIOR, L.C.; MARQUES, M.O.; NOGUEIRA, G.A. A Cultura do Amendoim. Jaboticabal, São Paulo, 220 p. 2004.

33.SINGH, J.; BARGALE, P.C. Development of a small capacity double stage compression screw press for oil expression. Journal of food engineering, v. 43, p. 75-82, 2000. DOI 10.1016/S0260-8774(99)00134-X

34.MEHER, L.C.; SAGAR, D.V.; NAIK, S.N. Technical aspects of biodiesel production by transesterification - a review. Renewable and Sustainable Energy Reviews, v. 10, p. 248 - 268, 2006. DOI 10.1016/j.rser.2004.09.002

35.KUCEK, K.T. et al. Ethanolysis of Refined Soybean Oil Assisted by Sodium and Potassium Hydroxides. Journal American Oil Chemist's Society. V.84, p. 385-392, 2007. DOI 10.1007/s11746-007-1048-2

36.ARAÚJO, J.M. de; OLIVEIRA, J.M.C. de; CARTAXO, W.V.; VALE, D.G.; SILVA, M.B. da. Vamos plantar amendoim. Campina Grande: Embrapa Algodão, 2000. 